\title{
Budget Impact Analysis of Warfarin Reversal Therapies Among Hip Fracture Patients in Finland
}

\author{
Timo Purmonen • Soili Törmälehto • \\ Niina Säävuori · Hannu Kokki
}

Published online: 7 March 2015

(c) The Author(s) 2015. This article is published with open access at Springerlink.com

\begin{abstract}
Background Hip fractures require operation within 36-48 h, and they are most common in the elderly. A high International Normalized Ratio should be corrected before surgery. In the current study, we analyzed the budget impact of various warfarin reversal approaches.

Methods Four reversal strategies were chosen for the budget impact analysis: the temporary withholding of warfarin, administration of vitamin $\mathrm{K}$, fresh frozen plasma (FFP), and a four-factor prothrombin complex concentrate (PCC).

Results We estimated that, annually, 410 hip fracture patients potentially require warfarin reversal in Finland. The least costly treatment was vitamin $\mathrm{K}$, which accounted for $€ 289,000$ in direct healthcare costs, and the most costly treatment option was warfarin cessation, which accounted for $€ 1,157,000$. In the budget impact analysis, vitamin $\mathrm{K}$, PCC and FFP would be cost-saving to healthcare compared with the current treatment mix.

Conclusion The various warfarin reversal strategies have different onset times, which may substantially impact the subsequent healthcare costs.
\end{abstract}

T. Purmonen $(\square) \cdot$ S. Törmälehto · N. Säävuori

Oy Medfiles Ltd, Volttikatu 5, P.O. Box 1450, 70701 Kuopio, Finland

e-mail: timo.purmonen@medfiles.eu

H. Kokki

Department of Anesthesiology and Intensive Care, School of Medicine, University of Eastern Finland, Kuopio, Finland

H. Kokki

Department of Anesthesia and Operative Services, Kuopio University Hospital, Kuopio, Finland

\section{Key Points}

Reversal of anticoagulation is required prior to surgery. Prevalence of anticoagulation therapy increases with aging population.

Method of anticoagulation reversal influences operation delay and medication costs. This should be taken into account when estimating the overall costs of treatment strategy options.

Budget impact analyses based on local patient population demonstrate the cost impact of adopting alternative treatment options. The method should be more widely used to support decision making.

\section{Introduction}

Finland has a population of 5.5 million, and the annual incidence of a first hip fracture is approximately 6000 [1]. Old age represents a major risk factor, and the incidence increases 13-fold from 60 to 80 years of age [2]. Although there is a continuous decreasing trend of age-adjusted incidence of hip fractures, based on the aging population and increasing life expectancy, the absolute number of hip fractures is likely to double during the next two decades [3].

Early surgery for hip fractures is encouraged. Operative delay beyond $48 \mathrm{~h}$ after admission may increase 30-day mortality by $41 \%$ [4]. The current guidelines promote surgery during the first 36-48 $\mathrm{h}$ after the fracture because the best available evidence indicates a reduction in mortality, complications, shortening of hospital stay, and 
earlier return to independent living with early compared with late surgery [5].

Most elderly patients have comorbidities, and patients must be medically optimized before surgery. In Finland, $12 \%$ of hip fracture patients must wait over $48 \mathrm{~h}$ for surgery [1]. One reason for the extended waiting times is the use of oral anticoagulants. In Finland, $8-16 \%$ of the elderly use warfarin [6], and the resulting anticoagulation should be reversed prior to surgery.

The reversal strategies include the temporary withholding of warfarin and the administration of vitamin $\mathrm{K}$, fresh frozen plasma (FFP), or prothrombin complex concentrate (PCC) [7, 8]. The choice of treatment method depends on the urgency of the anticoagulant effect reversal. Withholding warfarin is not a feasible method because the international normalized ratio (INR) may take 3-7 days to normalize. If $3 \mathrm{mg}$ of intravenous vitamin $\mathrm{K}$ is administered in addition to withholding warfarin, appropriate hemostatic function can be restored within $24 \mathrm{~h}$ in most patients with a therapeutic INR [9]. However, vitamin K may lack effectiveness in patients with supratherapeutic INR ratios, and patients should have normal liver function to synthesize and activate vitamin K-dependent clotting factors. FFP is a potential treatment of choice for hypovolemic patients who do not have anemia. However, a large infusion volume is required and may not be tolerated by patients with cardiac, renal, or pulmonary diseases. Four-factor PCCs contain coagulation factors II, VII, IX, and $\mathrm{X}$, and proteins $\mathrm{C}$ and $\mathrm{S}$. Therefore, they are highly effective in correcting INR as soon as they are in circulation. PCCs can be administered by short-term infusion without a risk of volume overload [7].

The four aforementioned reversal strategies have different onset times; therefore, the treatment choice substantially impacts the surgical operation delay. The budget impact of these various warfarin reversal approaches has not been established but should be considered in decision making. In the present study, we evaluated the costs of warfarin reversal from the perspective of a hospital in Finland and then evaluated the budget impact of PCC compared with the other three reversal strategies.

\section{Methods}

\subsection{Patient Population and Patient Characteristics}

In the present study, the incidence of 4418 hip fracture patients in Finnish hospitals in 2009 was applied based on the results of the Finnish PERFECT initiative [1]. This incidence includes community-dwelling patients with a first hip fracture episode in the past 10 years, patients older than 50 years, and a defined treatment period in the surgical unit [1]. The average age of the population was 78.8 years, and the prevalence of men was $31.8 \%$ [1]. The prevalence of hip fracture patients with warfarin therapy was estimated according to the Finnish population-based study of anticoagulant treatment [6]. Based on these data, we estimated that $8 \%$ of females and $12 \%$ of males in between the ages of 75 and 79 years received anticoagulant therapy. In this base-case analysis, the patients were assumed to have an initial INR of 3.0 and bodyweight of $70 \mathrm{~kg}$, which was assumed to reflect the average patient population. The target INR was assumed to be $\leq 1.5$.

\subsection{Questionnaire-Based Survey of Clinical Practice in Finland}

A questionnaire was mailed to all chief anesthetists $(n=27)$ at the secondary and tertiary care hospitals in Finland. The survey was performed in autumn 2012. The physicians were provided with a case scenario of a 75-yearold, community-dwelling patient (weighing $75 \mathrm{~kg}$, INR 3.0, hemoglobin $115 \mathrm{~g} / \mathrm{L}$, and hematocrit 0.33) with a hip fracture who had the last dose of warfarin for atrial fibrillation $20 \mathrm{~h}$ earlier. The anesthetists were asked to provide their anesthesia method, warfarin reversal method, and target INR in a case in which the patient would undergo surgery within the next $6 \mathrm{~h}$ and surgery and intrathecal anesthesia were contraindicated only because the INR ratio was 3.0. The respondents were also asked to specify their method of reversal in normovolemic and hypovolemic patients. Additionally, the dose regimen and combination of the reversal therapies (vitamin K, PCC, and FFP) and the dosage form of vitamin $\mathrm{K}$ were asked. The questionnaire used both multiple-choice and open-ended questions. The protocol was approved by the Research Ethics Committee of the Hospital District of Northern Savo, Kuopio, Finland (no. 60/2012).

\subsection{Methods of Anticoagulation Reversal}

The following four reversal strategies were chosen for the analysis (Table 1): the temporary withholding of warfarin, administration of vitamin K (Konakion Novum ${ }^{\circledR}$, Roche, Espoo, Finland), FFP (Octaplas ${ }^{\circledR}$ LG, Octapharma Nordic, Stockholm, Sweden), and a four-factor PCC (Cofact $^{\circledR}$, Sanquin, Amsterdam, the Netherlands). In the current treatment mix, 50/50 share of two commercial PCC preparations (PCC1: Cofact $^{\circledR}$, Sanquin, Amsterdam, the Netherlands and PCC2: Octaplex ${ }^{\circledR}$, Octapharma AG, Lachen, Switzerland) was assumed. Low molecular weight heparin (LMWH), enoxaparin sodium was considered as a bridging therapy during warfarin cessation and vitamin $\mathrm{K}$ treatment. The dose regimens that were applied in the analysis are presented in Table 1. 
Table 1 Warfarin reversal methods, dose regimens, prices, and incremental healthcare resource utilization rates applied in the base-case analysis (initial INR 3.0, target INR $\leq 1.5$, bodyweight $70 \mathrm{~kg}$ )

\begin{tabular}{|c|c|c|c|c|c|c|}
\hline \multirow[t]{2}{*}{ Treatment } & \multirow[t]{2}{*}{ Strength } & \multirow[t]{2}{*}{ Pack } & \multirow[t]{2}{*}{ Price per pack ${ }^{\mathrm{a}}$} & \multirow[t]{2}{*}{ Dose per day ${ }^{b}$} & \multicolumn{2}{|c|}{ Resource utilization rate } \\
\hline & & & & & Hospital days & INR testing \\
\hline FFP & $45-70 \mathrm{mg} / \mathrm{mL}$ & $200 \mathrm{~mL}$ & $€ 92.00$ & $15 \mathrm{~mL} / \mathrm{kg}$ & 1 & $6^{\mathrm{c}}$ \\
\hline \multirow[t]{2}{*}{$\mathrm{PCC}^{\mathrm{d}}$} & $250 \mathrm{IU}$ & $10 \mathrm{~mL}$ & $€ 172.50$ & $0.9 \mathrm{~mL} / \mathrm{kg}$ & 0 & 1 \\
\hline & $500 \mathrm{IU}$ & $20 \mathrm{~mL}$ & $€ 345.05$ & & & \\
\hline $\mathrm{PCC} 2^{\mathrm{d}}$ & $500 \mathrm{IU}$ & $20 \mathrm{~mL}$ & $€ 350.00$ & $1.6 \mathrm{~mL} / \mathrm{kg}$ & 0 & 1 \\
\hline Vitamin $\mathrm{K}$ & $10 \mathrm{mg} / \mathrm{mL}$ & $5 \times 1 \mathrm{~mL}$ & $€ 7.78$ & $1-3 \mathrm{mg}$ & 1 & $6^{\mathrm{c}}$ \\
\hline Warfarin withdrawal & & & & & 4 & $8^{\mathrm{c}}$ \\
\hline
\end{tabular}

FFP fresh frozen plasma, INR international normalized ratio, $I U$ international unit, $P C C 1$ prothrombin complex concentrate, Cofact ${ }^{\circledR}, P C C 2$ prothrombin complex concentrate, Octaplex ${ }^{\circledR}$

${ }^{a}$ Finnish drug database, wholesale prices 6.2.2014, excluding value added tax

b According to summaries of product characteristics (SPCs)

${ }^{c}$ Unit cost of INR testing (€8.63) is included in hospital day costs [10, 12]

d 50/50 share of two preparations in current treatment mix estimation

\subsection{Resource Use, Drug Costs, and Applied Values}

The study included factors that are related to anticoagulation reversal prior to emergency hip surgery during hospitalization in Finland (Table 1). The incremental costs that are caused by delayed operation include the laboratory (INR laboratory test) and hospitalization costs prior to operation. The costs of warfarin reversal were supplemented to estimate the total costs of the treated patient population. All healthcare unit costs were indexed to the 2013 value. The prices of the applied drug products were Finnish wholesale prices without value added tax (VAT) and without any discounts. Drug wastage was included in the medication costs (rounding up to the full packages). Medication costs under $€ 300 /$ day were omitted to avoid double counting with hospitalization costs (cost of vitamin $\mathrm{K}$ and enoxaparin sodium were less than $€ 300$ and, therefore, omitted). Different safety and adverse event profiles were not taken into account. Each individual treatment option represented a $100 \%$ treatment share in the analysis. In the later stage of the analysis, the treatment mix was estimated according to the survey of clinical practice in Finnish hospitals. The time range of the analysis was 1 year, including direct healthcare and drug costs that were related to the hip surgery hospitalization.

The resource use that was related to the various warfarin reversal methods was estimated according to the current clinical practice in Kuopio University Hospital. The chosen method affects the number of hospital days and INR tests needed during the treatment. The amount of additional resource use was related to the prolonged follow-up prior to surgery. In the base-case analysis, a unit cost of $€ 706$ for each hospital day in the traumatology treatment unit was used. The unit cost of a hospital day included medication costs that were less than $€ 300 /$ day and INR laboratory tests.
Finally, the cost of PCC treatment was compared with vitamin K, FFP, and cessation of warfarin therapy, and the budget impact of each individual treatment option compared with the current treatment mix was estimated.

\subsection{Sensitivity Analysis}

In the sensitivity analysis, patients were assumed to have an initial INR of 2.5, 3.0, or 3.5 and a bodyweight of 60 , 70 , or $80 \mathrm{~kg}$. The target INR was assumed to be $\leq 1.5$ in all scenarios. In addition, the unit cost of $€ 473$ (NordDRG system Diagnosis Related Group, DRG 236: fracture in hip or pelvis), $€ 706$ (traumatology treatment unit), and $€ 1077$ (DRG 211: surgery of hip or femur, adult, non-complicated) for each hospital day were used [11, 12]. The total healthcare cost of 27 scenarios was calculated. Also, the cost of two different PCC preparations (PCC1: Cofact $^{\circledR}$, Sanquin, Amsterdam, the Netherlands and PCC2: Octaplex ${ }^{\circledR}$, Octapharma AG, Lachen, Switzerland) were compared in a sensitivity analysis.

\subsection{Statistics}

The analysis was performed using MS Excel 2010 spreadsheet software (Microsoft Corporation, Redmond, WA, USA).

\section{Results}

\subsection{Cost Analysis}

It was estimated that, annually, 410 hip fracture patients require warfarin reversal in Finland. According to the base case results, the least costly treatment options for warfarin 
reversal were vitamin $\mathrm{K}$ and $\mathrm{PCC}$, which accounted for $€ 289,000$ and $€ 428,000$ direct healthcare costs, respectively (Fig. 1). The cost of vitamin $\mathrm{K}$ treatment depended on incremental inpatient days, whereas PCC-based treatment encompassed drug costs. The drug costs of PCC were partly offset by the reduced healthcare resource use. The most costly treatment, warfarin cessation, cost $€ 1,157,000$.

In the sensitivity analyses of 27 scenarios, vitamin $\mathrm{K}$ and PCC were the least costly treatment options in 70 and $30 \%$ of the scenarios, respectively (Table 2). In the same analyses, PCC, vitamin K, and FFP were ranked as the second least costly in 44, 30, and $26 \%$ of the scenarios, respectively. Furthermore, warfarin cessation was the most costly treatment option in all scenarios.

\subsection{Budget Impact Analysis}

To estimate the budget impact of the treatments, information on the current clinical practice was utilized to provide a baseline against which the alternative treatment scenarios were compared (Fig. 1). The proportion of each of the warfarin reversal treatment options that are used in current clinical practice was estimated based on the study questionnaire. The survey response rate among the chief anesthetists $(N=27)$ was $96 \%$. According to the survey, for patients with a high INR ratio, vitamin $\mathrm{K}$ would be administered for warfarin reversal in 20 of the 26 hospitals, PCC in 19 of the 26 hospitals, and FFP in 7 of the 26 hospitals. The combination of PCC and vitamin K would be the most common approach, followed by $\mathrm{PCC}$, vitamin $\mathrm{K}$, and triple therapy (PCC-FFP-vitamin K). Single therapy with FFP would be used in two hospitals, and FFP with vitamin $\mathrm{K}$ would be used in one hospital. Based on the survey, the current clinical practice of $37 \%$ (PCC1), $37 \%$ (PCC2), $12 \%$ (FFP), $15 \%$ (vitamin K), and $0 \%$ (warfarin withdrawal) were assumed to depict the average clinical practice in Finland. The transition from current practice to a $100 \%$ share of vitamin K, PCC1, or FFP would result in a negative budget impact (i.e., cost savings). However, the transition to warfarin withdrawal would result in extra annual healthcare costs.

Alternatively, if a $100 \%$ market share of each individual treatment option was assumed, the comparison between PCC and the other reversal options indicated that the

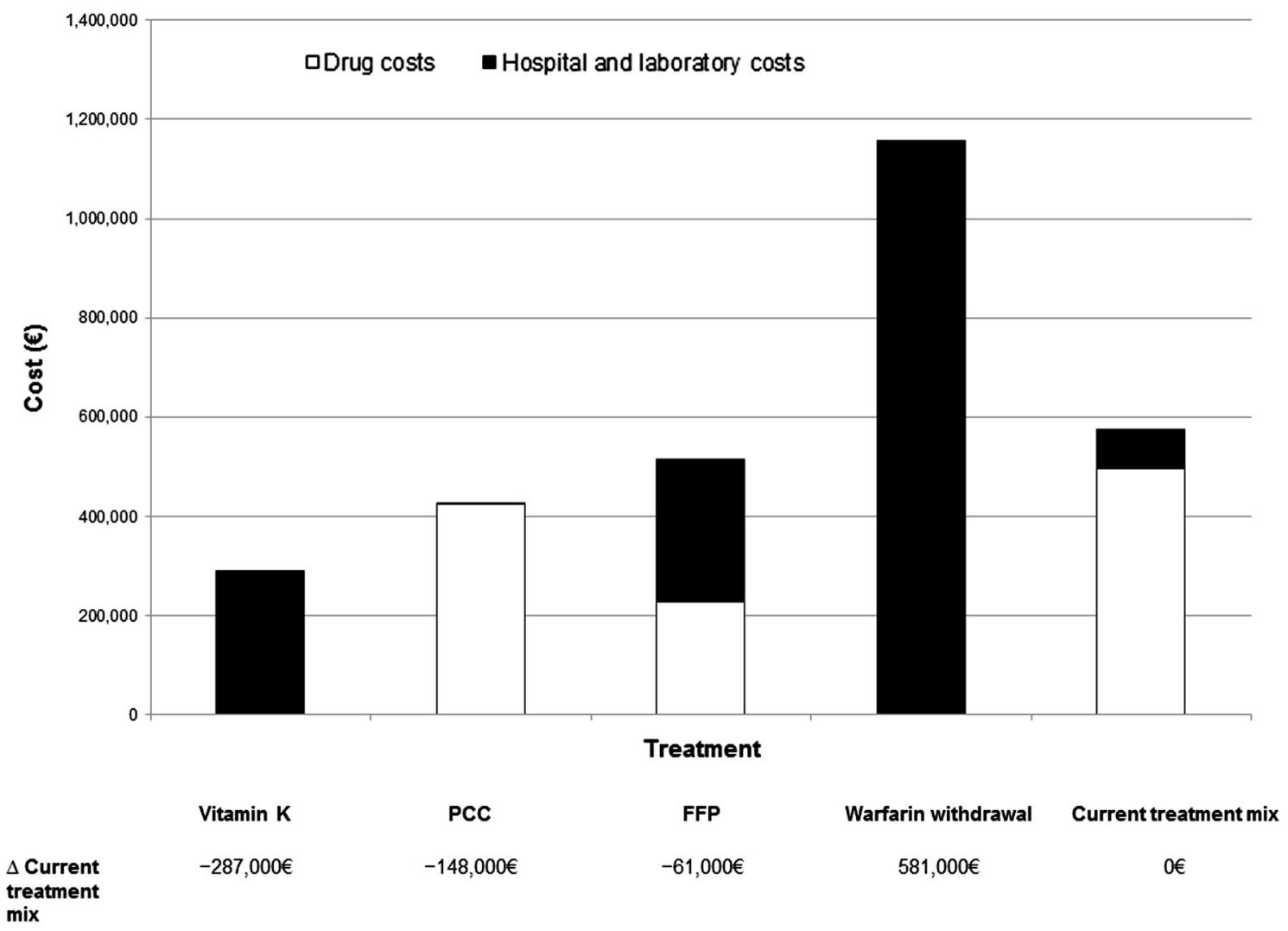

Fig. 1 Total costs of different warfarin reversal treatment options in hip fracture patients $(n=410)$ in Finland, base-case analysis (Initial INR 3.0; bodyweight $70 \mathrm{~kg}$, target INR $\leq 1.5$, incremental hospital day €706). Individual treatments represent $100 \%$ treatment share. Current treatment mix takes into account the current situation

according to a survey and 50/50 share of two PCC preparations. FFP fresh frozen plasma, INR international normalized ratio, $P C C$ prothrombin complex concentrate 
Table 2 Total costs $(x € 1000)$ of different warfarin reversal treatment options in hip fracture patients $(n=410)$ in Finland, one- and two-way sensitivity analysis (target INR $\leq 1.5$ )
$D R G 211$ surgery of hip or femur, adult, not complicated, $D R G 236$ fracture in hip or pelvis, $F F P$ fresh frozen plasma, INR international normalized ratio, $P C C$ prothrombin complex concentrate

a Incremental hospital day: traumatology unit (€706); DRG 236 (€473); DRG 211 (€1077)

b Includes bridging therapy

c Base case: initial INR 3.0; Bodyweight $70 \mathrm{~kg}$;

Traumatology unit

${ }^{d}$ PCC1 denotes for Cofact $^{\circledR}$ and PCC2 for Octaplex ${ }^{\circledR}$

\begin{tabular}{|c|c|c|c|c|c|}
\hline \multirow[t]{2}{*}{ Treatment } & \multirow[t]{2}{*}{ Bodyweight (kg) } & \multicolumn{3}{|l|}{ Inital INR } & \multirow[t]{2}{*}{ Incremental hospital day cost } \\
\hline & & $\begin{array}{l}\text { INR } 2.5 \\
(x € 1000)\end{array}$ & INR 3 & INR 3.5 & \\
\hline \multirow[t]{9}{*}{ Vitamin $\mathrm{K}^{\mathrm{b}}$} & \multirow[t]{3}{*}{60} & 194 & 194 & 194 & DRG 236 \\
\hline & & 289 & 289 & 289 & Traumatology unit \\
\hline & & 441 & 441 & 441 & DRG 211 \\
\hline & \multirow[t]{3}{*}{70} & 194 & 194 & 194 & DRG 236 \\
\hline & & 289 & $289^{c}$ & 289 & Traumatology unit \\
\hline & & 441 & 441 & 441 & DRG 211 \\
\hline & \multirow[t]{3}{*}{80} & 194 & 194 & 194 & DRG 236 \\
\hline & & 289 & 289 & 289 & Traumatology unit \\
\hline & & 441 & 441 & 441 & DRG 211 \\
\hline \multirow[t]{9}{*}{$\mathrm{PCC}^{\mathrm{d}}$} & \multirow[t]{3}{*}{60} & 286 & 357 & 428 & DRG 236 \\
\hline & & 286 & 357 & 428 & Traumatology unit \\
\hline & & 286 & 357 & 428 & DRG 211 \\
\hline & \multirow[t]{3}{*}{70} & 286 & 428 & 498 & DRG 236 \\
\hline & & 286 & $428^{c}$ & 498 & Traumatology unit \\
\hline & & 286 & 428 & 498 & DRG 211 \\
\hline & \multirow[t]{3}{*}{80} & 357 & 569 & 640 & DRG 236 \\
\hline & & 357 & 569 & 640 & Traumatology unit \\
\hline & & 357 & 569 & 640 & DRG 211 \\
\hline \multirow[t]{9}{*}{ FFP } & \multirow[t]{3}{*}{60} & 382 & 382 & 382 & DRG 236 \\
\hline & & 478 & 478 & 478 & Traumatology unit \\
\hline & & 630 & 630 & 630 & DRG 211 \\
\hline & \multirow[t]{3}{*}{70} & 420 & 420 & 420 & DRG 236 \\
\hline & & 515 & $515^{\mathrm{c}}$ & 515 & Traumatology unit \\
\hline & & 667 & 667 & 667 & DRG 211 \\
\hline & \multirow[t]{3}{*}{80} & 420 & 420 & 420 & DRG 236 \\
\hline & & 515 & 515 & 515 & Traumatology unit \\
\hline & & 667 & 667 & 667 & DRG 211 \\
\hline \multirow[t]{9}{*}{$\mathrm{PCC} 2^{\mathrm{d}}$} & \multirow[t]{3}{*}{60} & 577 & 720 & 864 & DRG 236 \\
\hline & & 577 & 720 & 864 & Traumatology unit \\
\hline & & 577 & 720 & 864 & DRG 211 \\
\hline & \multirow[t]{3}{*}{70} & 720 & 864 & 864 & DRG 236 \\
\hline & & 720 & 864 & 864 & Traumatology unit \\
\hline & & 720 & 864 & 864 & DRG 211 \\
\hline & \multirow[t]{3}{*}{80} & 864 & 864 & 864 & DRG 236 \\
\hline & & 864 & 864 & 864 & Traumatology unit \\
\hline & & 864 & 864 & 864 & DRG 211 \\
\hline \multirow[t]{9}{*}{ Warfarin withdrawal ${ }^{\mathrm{b}}$} & \multirow[t]{3}{*}{60} & 776 & 776 & 776 & DRG 236 \\
\hline & & 1157 & 1157 & 1157 & Traumatology unit \\
\hline & & 1765 & 1765 & 1765 & DRG 211 \\
\hline & \multirow[t]{3}{*}{70} & 776 & 776 & 776 & DRG 236 \\
\hline & & 1157 & $1157^{\mathrm{c}}$ & 1157 & Traumatology unit \\
\hline & & 1765 & 1765 & 1765 & DRG 211 \\
\hline & 80 & 776 & 776 & 776 & DRG 236 \\
\hline & & 1157 & 1157 & 1157 & Traumatology unit \\
\hline & & 1765 & 1765 & 1765 & DRG 211 \\
\hline
\end{tabular}


total healthcare costs of PCC treatment would be higher $(+€ 139,000)$ compared with vitamin K (Fig. 1). However, the budget impact of PCC would be cost-saving (-€729,000, and -€87,000) compared with warfarin withdrawal and FFP, respectively.

\section{Discussion}

The present cost analysis of warfarin reversal therapies indicated that vitamin $\mathrm{K}$ and PCC were the least costly warfarin reversal treatment options if direct healthcare costs during hospitalization prior to the hip fracture surgery were considered. Vitamin $\mathrm{K}$ induced costs solely because of resource utilization due to operation delay, whereas PCC prompted extra drug costs. However, the drug costs of PCC were partly offset by savings in resource utilization, as the operation delay was avoided. According to the budget impact analysis, vitamin K, PCC, and FFP were profitable if the current treatment mix was replaced by a $100 \%$ market share of each individual treatment option. However, different safety profiles and contraindications may affect the clinical implementation of treatment options, which cannot be defined in monetary terms. The present budget impact analysis was applied to the Finnish healthcare system. Utilization of local cost and resource use data is a relevant approach in economic evaluations. However, this may affect the generalizability of the results across regions. Potential bias arising from uncertainty in cost estimates was reduced by using two extremes of hip fracture treatment costs (DRG 211 and DRG 236) in the sensitivity analyses.

Most patients with hip fractures are frail and have comorbidities. Operation delays lengthen the hospital stay and may increase mortality [13-15]. Early surgery reduces mortality; therefore, the current guidelines recommend surgery during the first 36-48 h after the hip fracture [5]. One reason that an operation may be delayed is the patient's use of oral anticoagulants. The action of these anticoagulants should be reversed prior to the surgery to establish appropriate hemostatic function and to optimize the choice of anesthesia. The temporary withholding of warfarin is not feasible in emergency surgery, as it may take up to 5 days to establish appropriate hemostatic function. Proper reversal strategies include the administration of vitamin K, FFP, or a four-factor PCC, and the choice of treatment method depends on the urgency of the anticoagulant effect reversal [7, 8]. The various approaches may have significant budget impacts. Furthermore, in contrast to elective surgery, it is not consistently possible to predict when an emergency care patient can be admitted to surgery. Therefore, the system must be flexible so that the surgery can be performed in a timely manner.
The cost analysis favored vitamin $\mathrm{K}$ as an anticoagulation reversal therapy. The spontaneous reversal of anticoagulation by temporary warfarin cessation takes several days. As warfarin acts as a vitamin $\mathrm{K}$ antagonist, the reversal of anticoagulation is achieved more rapidly with the concomitant administration of oral vitamin $\mathrm{K}$ [7, 16, 17]. If $1 \mathrm{mg}$ of oral vitamin $\mathrm{K}$ is given $24 \mathrm{~h}$ before surgery, an INR ratio can be normalized in some patients and correlates with short duration of bridging therapy [18]. However, one-third of patients fail to respond to these lower doses [19]. Intravenous vitamin $\mathrm{K}$ produces a more prompt and complete reduction in the INR ratio than does oral or subcutaneous vitamin $\mathrm{K}$ [7, 20-22]. If $3 \mathrm{mg}$ of intravenous vitamin $\mathrm{K}$ is administered in addition to the withholding of warfarin, appropriate hemostatic function can be restored within $24 \mathrm{~h}$ in $90 \%$ of patients [9]. However, the desired ratio is not achieved in all patients. Vitamin $K$ is less effective in patients with supratherapeutic INR ratios, and patients who receive vitamin $\mathrm{K}$ should have normal liver function to synthesize and activate vitamin K-dependent clotting factors. Moreover, after vitamin $\mathrm{K}$ administration it may take 2-11 days to re-establish a therapeutic INR ratio [9]. Therefore, patients may require bridging therapy with LMWH and repeated INR testing for up to 2 weeks after the surgery. Bridging therapy induces extra resource utilization and costs. Therefore, vitamin $\mathrm{K}$ administration is not an optimal approach in hip fracture surgery.

The cost analysis also favored PCC. The anticoagulant effect of warfarin is mediated by the reduced coagulant activity of four vitamin K-dependent clotting factors, II, VII, IX, and X [7]. Prothrombin complex concentrates are categorized as three- and four-factor products. Three-factor products contain low concentrations of factor VII, whereas four-factor PCCs contain factors II, VII, IX, and X and proteins $\mathrm{C}$ and $\mathrm{S}$. Therefore, four-factor PCCs are highly effective in correcting INR ratios as soon as they are in circulation [7]. With PCCs, a blood type definition is not required. Furthermore, they are virally inactivated and can be administered as a short-term infusion with no risk of volume overload [7].

FFP products are indicated for the rapid reversal of the effects of oral anticoagulants if vitamin $\mathrm{K}$ is insufficient because of impaired liver function or in emergency situations. However, PCCs reverse anticoagulation more rapidly and effectively and have a better safety profile than FFP [23-26]. Additionally, the therapeutic volume of PCC is $1-2 \mathrm{~mL} / \mathrm{kg}$, whereas FFP is administered in volumes of $15 \mathrm{~mL} / \mathrm{kg}$ or higher [26]. These higher volumes are associated with an increased risk of volume overload; therefore, prolonged infusion times are required [26, 27]. Although FFP may be the treatment of choice in hypovolemic hip fracture patients with a normal hematocrit value, in patients with blood loss or anemia, large doses of FFP may impair 
hemostatic function by decreasing the hematocrit. Moreover, FFP may contain only $55-85 \%$ of the physiological concentrations of clotting factors [28]. Therefore, to ensure that a patient is given, for example, $1000 \mathrm{IU}$ of coagulation factor IX, the infusion volume should be between 1200 and $1800 \mathrm{~mL}$. If the generally accepted starting dose of $15 \mathrm{~mL} /$ $\mathrm{kg}$ is given, a patient with a bodyweight of $70 \mathrm{~kg}$ may receive only $600-900 \mathrm{IU}$ of factor IX. This value is significantly less than that of $1500 \mathrm{IU}$ of $60 \mathrm{~mL}$ of PCC.

The various PCCs that are marketed in Finland have different dosing guidelines (according to the summaries of product characteristics [SPCs]), and different package sizes, and hence different costs; therefore, two commercial preparations were taken into account in the current treatment mix. The recommended doses of PCC1 vary between 0.4 and $1.3 \mathrm{~mL} / \mathrm{kg}$ depending on the initial INR, bodyweight, and target INR $[29,30]$. The recommended doses of PCC 2 vary between 0.9 and $2.0 \mathrm{~mL} / \mathrm{kg}$ (maximum dose $120 \mathrm{~mL}$ ) [31]. Additionally, the availability of different package sizes (PCC1) potentially decreases drug wastage and thus decreases costs.

There are some limitations in the present study. Firstly, the budget impact analysis is based on the Finnish price level. Thus, the results should be interpreted with caution in other regions. Secondly, in respect of the treatment protocols, the study is based on a survey with a limited number of local anesthesiologists. Nevertheless, the budget impact analyses are according to dosages arising from summaries of product characteristics. Despite the limitations, the results provide a reasonable estimate of the local clinical situation. Also, in order to take into account the variation in dosage regimen, the sensitivity analyses were applied for various bodyweights and initial INR values.

New oral anticoagulants, apixaban, dabigatran and rivaroxaban, have recently been approved as an alternative for warfarin in some indications such as in patients with non-valvular atrial fibrillation. One of the limitations of these new compounds is that there are no specific antidotes for any of these new compounds. It is recommended to defer procedures that carry a risk for major bleeding or bleeding into a close compartment until at least $24-48 \mathrm{~h}$ after the last dose. However, no guidelines or strategies for the reversal of the anticoagulant effects of these compounds have ever been evaluated in clinical settings. Thus, no recommendation on how to handle hip fracture patients taking new oral anticoagulants can be given at this time [32].

\section{Conclusion}

In conclusion, the four reversal strategies (i.e., the temporary withholding of warfarin, administration of vitamin $\mathrm{K}$,
FFP, or a four-factor PCC) have different times of onset, which substantially impact the surgical operation delay and healthcare costs. Economic evaluations are performed to help decision makers allocate scarce resources effectively, and budget impact analysis is employed to evaluate the consequences of the implementation of new treatments in practice. The present budget impact analysis indicated that a low dose of vitamin $\mathrm{K}$ and PCC are the most economical options for warfarin reversal. This result should be considered in decision making and clinical practice.

Acknowledgments This study was conducted by Oy Medfiles Ltd, Kuopio, Finland (T.P., S.T., N.S.), and supported by Sanquin Oy, Espoo, Finland. T.P., S.T., and N.S. did not receive direct funding from Sanquin Oy. H.K. received a lecture fee from Octapharma Nordic, Stockholm, Sweden, and travel funding for a medical congress from Sanquin Oy, Espoo, Finland. No sponsor played a role in the data analysis, the interpretation of the results, or the decision to submit the manuscript for publication.

Open Access This article is distributed under the terms of the Creative Commons Attribution Noncommercial License which permits any noncommercial use, distribution, and reproduction in any medium, provided the original author(s) and the source are credited.

\section{References}

1. Sund R, Juntunen M, Lüthje P, Huusko T, Mäkelä M, Linna M, Liski A, Häkkinen U. PERFECT-Lonkkamurtuma. Hoitoketjujen toimivuus, vaikuttavuus ja kustannukset lonkkamurtumapotilailla. (PERFECT, PERFormance, Effectiveness and Cost of Treatment episodes: Hip fractures) Report of a PERFECT working party, Helsinki, original report 2008, updated 2012. http://www. thl.fi/fi_FI/web/fi/tutkimus/hankkeet/perfect/lonkkamurtuma/ perusraportit. Accessed 21 Mar 2014.

2. de Laet CE, van Hout BA, Burger H, Hofman A, Pols HA. Bone density and risk of hip fracture in men and women: cross sectional analysis. BMJ. 1997;26:221-5.

3. Korhonen N, Niemi S, Parkkari J, Sievänen H, Palvanen M, Kannus P. Continuous decline in incidence of hip fracture: nationwide statistics from Finland between 1970 and 2010. Osteoporos Int. 2013;24:1599-603.

4. Shiga T, Wajima Z, Ohe Y. Is operative delay associated with increased mortality of hip fracture patients? Systematic review metaanalysis and meta-regression. Can J Anesth. 2008;55:135-9.

5. National Clinical Guideline Centre. The management of hip fracture in adults. London: National Clinical Guideline Centre; 2011. www.ncgc.ac.uk. Accessed 21 Mar 2014.

6. Virjo I, Mäkelä K, Aho J, Kalliola P, Kurunmäki H, Uusitalo L, Valli $\mathrm{M}$, Ylinen $\mathrm{S}$. Who receives anticoagulant treatment with warfarin and why? A population-based study in Finland. Scand J Prim Health Care. 2010;28:237-41.

7. Ageno W, Gallus AS, Wittkowsky A, Crowther M, Hylek EM, Palareti G, American College of Chest Physicians. Oral anticoagulant therapy: antithrombotic therapy and prevention of thrombosis, 9th ed: American college of chest physicians evidence-based clinical practice guidelines. Chest. 2012;141(2 Suppl):e44S-88S.

8. Ageno W, Garcia D, Aguilar MI, Douketis J, Finazzi G, Imberti D, Iorio A, Key NS, Lim W, Marietta M, Prisco D, Sarode R, 
Testa S, Tosetto A, Crowther M. Prevention and treatment of bleeding complications in patients receiving vitamin $\mathrm{K}$ antagonists, part 2: Treatment. Am J Hematol. 2009;84:584-8.

9. Burbury KL, Milner A, Snooks B, Jupe D, Westerman DA. Shortterm warfarin reversal for elective surgery-using low-dose intravenous vitamin $\mathrm{K}$ : safe, reliable and convenient*. Br J Haematol. 2011;154:626-34.

10. Hujanen T, Kapiainen S, Tuominen U, Pekurinen M. Terveydenhuollon yksikkökustannukset Suomessa vuonna 2006. (Health care unit cost in Finland in 2006). Report of National Institute for Health and Welfare, Helsinki, Finland 2008. http://www.julkari. fi/handle/10024/76754. Accessed 21 Mar 2014.

11. NordDRG system Diagnosis Related Group. Helsinki: Nordic Casemix Centre; 2011. http://www.nordcase.org/. Accessed 21 Mar 2014.

12. Kapiainen S, Väisänen A, Haula T. Terveyden- ja sosiaalihuollon yksikkökustannukset Suomessa vuonna 2011. (Social- and health care unit costs in Finland in 2011). Report of National Institute for Health and Welfare, Helsinki, 2014. http://www.julkari.fi/ handle/10024/114683. Accessed 21 Mar 2014.

13. Siegmeth AW, Gurusamy K, Parker MJ. Delay to surgery prolongs hospital stay in patients with fractures of the proximal femur. J Bone Jt Surg Br. 2005;87:1123-6.

14. Weller I, Wai EK, Jaglal S, Kreder HJ. The effect of hospital type and surgical delay on mortality after surgery for hip fracture. J Bone Jt Surg Br. 2005;87:361-6.

15. Bergeron E, Lavoie A, Moore L, Bamvita JM, Ratte S, Gravel C, Clas D. Is the delay to surgery for isolated hip fracture predictive of outcome in efficient systems? J Trauma. 2006;60:753-7.

16. Dentali F, Ageno W, Crowther M. Treatment of coumarin-associated coagulopathy: a systematic review and proposed treatment algorithms. J Thromb Haemost. 2006;4:1853-63.

17. Leonidou A, Rallan R, Cox N, Pagkalos J, Luscombe J. Comparison of different warfarin reversal protocols on surgical delay and complication rate in hip fracture patients. J Orthop Surg (Hong Kong). 2013;21:142-5.

18. Woods K, Douketis JD, Kathirgamanathan K, Yi Q, Crowther MA. Low-dose oral vitamin $\mathrm{K}$ to normalize the international normalized ratio prior to surgery in patients who require temporary interruption of warfarin. J Thromb Thrombolysis. 2007;24:93-7.

19. Steib A, Barre J, Mertes M, Mertes M, Morel MH, Nathan N, Ozier Y, Treger M, Samama CM. Can oral vitamin K before elective surgery substitute for preoperative heparin bridging in patients on vitamin $\mathrm{K}$ antagonists? $\mathrm{J}$ Thromb Haemost. 2010;8:499-503.

20. Nee R, Doppenschmidt D, Donovan DJ, Andrews TC. Intravenous versus subcutaneous vitamin $\mathrm{K} 1$ in reversing excessive oral anticoagulation. Am J Cardiol. 1999;83(286-8):A6-7.
21. Raj G, Kumar R, McKinney WP. Time course of reversal of anticoagulant effect of warfarin by intravenous and subcutaneous phytonadione. Arch Intern Med. 1999;159:2721-4.

22. Lubetsky A, Yonath H, Olchovsky D, Loebstein R, Halkin H, Ezra D. Comparison of oral vs intravenous phytonadione (vitamin K1) in patients with excessive anticoagulation: a prospective randomized controlled study. Arch Intern Med. 2003;163:2469-73.

23. Holland LL, Brooks JP. Toward rational fresh frozen plasma transfusion: The effect of plasma transfusion on coagulation test results. Am J Clin Pathol. 2006;126:133-9.

24. Schick KS, Fertmann JM, Jauch KW, Hoffmann JN. Prothrombin complex concentrate in surgical patients: retrospective evaluation of vitamin $\mathrm{K}$ antagonist reversal and treatment of severe bleeding. Crit Care. 2009;13:R191.

25. Demeyere R, Gillardin S, Arnout J, Strengers PF. Comparison of fresh frozen plasma and prothrombin complex concentrate for the reversal of oral anticoagulants in patients undergoing cardiopulmonary bypass surgery: a randomized study. Vox Sang. 2010;99:251-60.

26. Franchini M, Lippi G. Prothrombin complex concentrates: an update. Blood Transfus. 2010;8:149-54.

27. Bruce D, Nokes TJ. Prothrombin complex concentrate (Beriplex $\mathrm{P} / \mathrm{N}$ ) in severe bleeding: experience in a large tertiary hospital. Crit Care. 2008;12:R105.

28. Theusinger OM, Baulig W, Seifert B, Emmert MY, Spahn DR, Asmis LM. Relative concentrations of haemostatic factors and cytokines in solvent/detergent-treated and fresh-frozen plasma. Br J Anaesth. 2011;106:505-11.

29. van Aart L, Eijkhout HW, Kamphuis JS, Dam M, Schattenkerk ME, Schouten TJ, Ploeger B, Strengers PF. Individualized dosing regimen for prothrombin complex concentrate more effective than standard treatment in the reversal of oral anticoagulant therapy: an open, prospective randomized controlled trial. Thromb Res. 2006;118:313-20.

30. SPC, Summary of product characteristics: Cofact $^{\circledR} 250 \mathrm{IU}$ and $500 \mathrm{IU}$ powder and solvent for solution for injection (Sanquin). http://www.sanquin.nl/repository/documenten/en/prod-en-dienst/ plasmaproducten/Cofact/Summary_of_product_characteristics. pdf. Accessed 21 Mar 2014.

31. SPC, Summary of product characteristics: Octaplex ${ }^{\circledR} 500 \mathrm{IU}$ powder and solvent for solution for infusion (Octapharma). http:// www.octapharma.ca/fileadmin/user_upload/octapharma.ca/2012 0613_PM_Octaplex_approved.pdf. Accessed 24 Apr 2014.

32. Heidbuchel H, Verhamme P, Alings $M$, Antz M, Hacke W, Oldgren J, Sinnaeve P, Camm AJ, Kirchhof P. EHRA practical guide on the use of new oral anticoagulants in patients with nonvalvular atrial fibrillation: executive summary. Eur Heart $\mathrm{J}$. 2013;34:2094-106. 